\title{
Mão na Luva - quando o teatro dançou Uma preparação corporal de Klauss Vianna
}

Joana Ribeiro

"Ele - (...) Sabe por que é que eu te amo? O teu tempo é assim parecido com o tempo das coisas. Você nunca sente aquela necessidade de ser imprevista. Feito trigo nascendo. Mulher longa. Você é feito tomar banho de cascata. Sabe o que quer, sabe o que te querem, junta os dois juntos. Você é mão na luva. (Chama-a:) Mão na luva.

$$
\begin{aligned}
& \text { Ela - Hein? } \\
& \text { Ele - Mão na luva. } \\
& \text { Ela - Hein? (Se beijam.) } \\
& \text { (Reversão de luz. Tempo presente.)" }
\end{aligned}
$$

Mão na Luva foi escrita por Oduvaldo Vianna Filho (1936-1974), mais conhecido como Vianinha, em 1966, e batizada inicialmente como Corpo a Corpo. É uma peça que destoa da obra do autor, de cunho notadamente sócio-político, retratando em geral o povo brasileiro com seus costumes e conflitos, como em Rasga Coração, Papa Highirte e Chapetuba Futebol Clube, só para citar algumas. Sobre isso, basta lembrar que Vianinha participou de importantes grupos de teatro, nas décadas de 50 e 60 , tais como o Teatro de Arena, em São Paulo, o CPC e o Opiniăo, no Rio de Janeiro, responsáveis pela valorização da dramaturgia brasileira. Talvez por isso tenha guardado Măo na Luva na "gaveta", reutilizando o seu título original Corpo a Corpo, na peça que escreveu posteriormente, em 1970. Vianinha nāo pôde assistir à estréia de Mão na Luva, dirigida por Aderbal Freire Filho, em 1984 - faleceu prematuramente, vitima de câncer, aos trinta e oito anos - nem tampouco, soube do novo batismo da sua peça, como Mão na Luva, uma expressão que Antônio Mercado, seu leitor póstumo, retirou do texto.

O diretor Aderbal Freire já havia montado no Rio de Janeiro outras peças de Vianinha, tais como: Corpo a Corpo, em 1975, com Gracindo Júnior e Moço em Estado de Sítio, em 1981, que valeu ao dramaturgo um Molière póstumo, e a Aderbal, o Moliè-

Joana Ribeiro é atriz-bailarina e coreógrafa, doutoranda em Artes Cênicas pela UNIRIO e professora da Faculdade Angel Vianna. Dançou em companhias como Deborah Colker, e coreografou e atuou, entre outros, nos quatro cabarés dirigidos por Domingos Oliveira. 
re de melhor direção. Deste modo, conheceu a viúva de Vianinha, Maria Lúcia Vianna, que lhe apresentou a ainda inédita Mão na Luva, com a qual se encantou de imediato. Quando o ator Marco Nanini o convidou para dirigi-lo na peça Senhorita Júlia, de Strindberg, em 1984, Aderbal sugeriu montar Mão na Luva, assegurando que o ator faria o papel de Lúcio Paulo com esplendor. O que consistiu num desafio para Nanini, que considerava o personagem complicado, diferente de suas experiências anteriores voltadas para a comédia, exigindo-lhe uma interpretaçăo mais sutil.

Nanini e Aderbal resolveram, então, encená-la em São Paulo e convidaram a atriz Renata Sorrah, entre outras, para uma primeira leitura. Renata indicou a atriz Juliana Carneiro da Cunha, com quem havia trabalhado em As lágrimas amargas de Petra von Kant, de Fassbinder, dirigida por Celso Nunes, numa produção do Teatro dos Quatro com Fernanda Montenegro, em 1982, no Rio de Janeiro. Para formar a equipe técnica de Mão na Luva, Nanini convocou Klauss Vianna, que residia na época em São Paulo, e este trouxe consigo o percussionista João de Bruçó, que costumava acompanhá-lo nas suas aulas e com quem trabalhou depois, no projeto de sua última coreografia Dã-dá Corpo, em 1985. Completaram a ficha técnica o cenógrafo e figurinista Márcio Colaferro, o diretor musical Marcos Leite e o próprio Aderbal, como iluminador. A montagem estreou em São Paulo no Teatro Maria Della Costa, em setembro de 1984, onde permaneceu em cartaz por três meses, e foi para o Teatro Gláucio Gill, no Rio de Janeiro, cumprindo uma temporada de, aproximadamente, seis meses.

Mão na Luva é dividida em dois atos, apresentando a separação de um casal, identificados inicialmente apenas, como Ele e Ela, mas que no final sāo chamados por seus nomes próprios, Lúcio Paulo Freitas e Sílvia. A ação se desenrola durante a noite em que ela resolve se separar do marido. Ele pede uma explicação para a decisão da mulher, que é apresentada pelo autor no formato de flash-back, onde os fatos do passado justificam e esclarecem as atitudes do presente. Um recurso de contraponto cronológico, que perpassa pela obra de Vianinha, alcançando seu apogeu na derradeira Rasga Coração, em 1974. Mas o que diferencia Mão na Luva das outras peças do autor é justamente o seu tema, o relacionamento amoroso de um casal, representado por diálogos de um lirismo desenfreado, num momento em que o enfoque no teatro voltava-se para temas predominantemente políticos. O que, entretanto, não impediu Vianinha de contextualizar, historicamente seus personagens, posicionando-os frente aos acontecimentos, vivenciados durante o regime militar, na década de 60 , como declarou Nanini: “(...) Vianinha não abandona o discurso que sempre o guiou, mas faz uma revisāo crítica do homem de esquerda dentro de sua própria casa." ${ }^{2}$

Ele é um jornalista acomodado, que desiste de seus ideais revolucionários, em favor da segurança do emprego numa revista, na qual não acredita. Ela é uma dona de casa que se refugia nos afazeres domésticos, como cuidar do sítio do casal, abdicando de suas pretensões como artista e aceitando o declínio ideológico do marido. Um casal em crise, após nove anos de convívio, que resolve expor durante a separação todos os fatos desagradáveis que fingiam aceitar, como a traição conjugal. Mas que se reconci- liam, como se fossem condenados a viver juntos para sempre, como sentencia o marido, quando ela volta para casa, no final.

Aderbal divide os primeiros ensaios de uma peça em dois momentos, o tempo de conhecimento, onde a equipe busca todo o material que concerne o tema da peça, e o tempo de expressar o conhecer, quando os personagens são construídos. E ressalta como o trabalho de Klauss Vianna foi fundamental em ambos processos. Na primeira fase, Klauss desempenhou a funçāo de preparador corporal, conduzindo um aquecimento com exercícios e improvisaçōes. Um fato curioso foi a decisão de que toda a equipe técnica participaria dessa fase, uma conduta incentivada por Nanini, que considerava a aula de corpo importante nāo só para a construção dos personagens, quanto para a integraçăo do grupo. Conforme o diretor, Klauss aplicava um aquecimento corporal enfatizando o relaxamento muscular, o que contrariava os treinos correntes na época, que tensionavam o corpo excessivamente, prendendo os movimentos. Aderbal, inclusive costumava brincar dizendo que eles poderiam revolucionar o futebol, implementando a nova técnica estabelecida por Klauss, para evitar que os jogadores se contundissem com tanta frequiência. Pois o coreógrafo alegava que a repetição de exercícios mal orientados, executados sem o encaixe correto das articulaçōes, contribuía para a formação de uma musculatura neurótica, característica nas pernas dos jogadores de futebol.

Nessa fase preparatória a expressão corporal dos atores foi bastante requisitada, linguagem essa que foi decifrada no final dos anos 60 e considerada depois da morte de Vianinha, em 1974, como uma atitude de total alienação pelos engajados políticos, mas que nesta releitura, dez anos depois, traduziu com apuro a dramaturgia do autor. Sobre isso, Klauss Vianna declarou que na década de 60 , o ator só tinha a voz, o que o levou a enfocar os bloqueios do próprio Vianinha, típicos de uma geração politizada, puramente racional. E acrescenta que os exercícios diários feitos durante um mês e meio, buscaram desenhar na musculatura dos atores, a história das tensōes comuns nos relacionamentos amorosos, ou seja, a história do herói e do anti-herói, descrita na peça. Segundo Nanini, esses exercícios mexiam com os músculos da emoção, reconhecendo-os como uma técnica autêntica, que insere Klauss Vianna no rol dos melhores profissionais em corpo, o que estimulou no seu corpo, a descoberta dos músculos internos, notadamente os adutores, através de uma intensa pesquisa de movimento. ${ }^{3}$

Klauss admite, que em alguns ensaios, chegou a prender as mãos de Nanini, pois estavam viciadas expressivamente ${ }^{4}$, para que $o$ ator procurasse diferentes expressóes com o resto do corpo. Esse procedimento parece ter resultado na postura, assumida pelo ator em cena, em que a coluna vertebral funcionava como condutora dos movimentos, pois que as extremidades - os membros superiores - haviam sido presas, durante os ensaios. Juliana Carneiro, que conhecia Klauss Vianna desde 1976, quando ela lecionou dança-teatro, na escola Martins Penna, no Rio de Janeiro, lembra dessas aulas diárias, ministradas durante os ensaios. E enfatiza a consciência corporal, que adquiriu, com destaque para os músculos adutores ${ }^{5}$, ignorados até então por ela, que eram trabalhados "desde os dedos dos pés, até o rosto (...) num trabalho 
fascinante! $!^{6}$ Sobre isso, Nanini acrescenta que o coreógrafo aplicava muitos exercícios de alongamento, buscando sempre a imagem de uma espiral muscular. O que proporcionava uma compreensão corporal, que impulsionava o movimento, com uma rapidez superior àquela decorrente dos processos habituais de massificação de exercícios. A segunda contribuição de Klauss, além da preparação corporal, preciosa para a montagem, diz respeito ao aperfeiçoamento das marcaçōes do diretor:

“(...) quando eu trabalho com preparadores corporais, o que eu quero deles é uma preparação física, corporal, dos atores e muitas vezes o aprimoramento das marcaçōes. Isso teve sobretudo com o Klauss, na Mão na Luva. Era perfeita a execução, porque eu marcava uma cena, que os atores começavam em cima da mesa e terminavam em baixo, passando pela cadeira e tal. A marcação, diria que foi minha - não simplesmente pedir algo ao Klauss e ele ter que se virar para resolver, mas a própria execução - que depois era trabalhada pelo Klauss, como por exemplo, que pé apoiava na mesa, e como ele fazia isso, nunca mais encontrei igual. ${ }^{7}$

Juliana cita uma cena de briga em que ela e Nanini saíam do chāo e paravam em cima de uma mesa, que era toda ritmada e coreografada, sem o que eles poderiam se machucar de verdade. $\mathrm{O}$ que reforça como o trabalho de Klauss Vianna ofereceu valiosa ferramenta, habilitando os atores tecnicamente para cumprirem suas marcaçōes sem desgaste físico, mediante suas dicas preciosas. ${ }^{8}$ Esse aprimoramento das marcaçōes, segundo Nanini, apesar de ser milimétrico era realizado de modo orgânico, para que a intenção da fala transparecesse nos movimentos. O que resultou numa movimentaçăo marcadíssima, que facilitava as passagens bruscas de emoçăo, que permeavam o texto. A presença constante de flash-back, que alterna as açōes do presente onde o casal discute - com as açōes do passado - em que eles revivem momentos de intensa alegria - é indicada nas rubricas, não só pela mudança de luz, como também pela repetição de movimentos. Que deveriam ser executados de modo distinto, para significar a passagem de tempo, justificando a necessidade de um especialista em técnica corporal, como acrescenta Nanini:

"(...) havia passados e presentes muito bruscos, e muito desgastantes, porque você vinha numa briga, às vezes muito violenta e isso era interrompido, para em segundos, voltar ao passado feliz (...) de início de namoro. Essa quebra tumultuava muito o corpo, até ele receber essa informação precisava de um treino.." ${ }^{9}$

$\mathrm{Na}$ gravação da peça ${ }^{10}$, verifica-se como as indicaçōes gestuais das rubricas não foram apenas marcadas, mas também coreografadas, sendo que os mesmos gestos são repetidos em silêncio, criando uma partitura corporal, ritmada em câmara lenta, que se configura num verdadeiro duo de dança. Aliás, a indicação de dança, notadamente a valsa, percorre toda a peça e serve, igualmente, como recurso para significar a passagem de tempo:

“(...) Ela - Te comprei uma gravata e abotoadura para ir na audiência... (Ele sorri. Vem para Ela. Pega-a para dançar. Dançam.)

(Reversão de luz, flash-back)
Os dois dançam, mais alegres

Ela - Tem gente demais olhando, olha. (Ele ri)

Ele - Que você está dançando?

Ela - Eu, valsa.

Ele - Também vou dançar valsa, entăo. Estava pensando em blues.

(Riem. Valsam) Daqui a pouco você corre o chapéu... (Riem e dançam)

(Reversão de luz. Tempo presente)

(Dançam quietos, de rosto colado, um longo tempo)."

“(...) Ela - Pára, meu amor, pára. Pára. (Se abraçam)

(Reversão de luz. Flash-back)

(Dançam)

Ela - Tem gente demais olhando, olha. (Ele ri)

Ele - Que você está dançando?

Ela - Eu, valsa.

Ele - Também vou dançar valsa, entāo. (Valsam)

(Reversăo de luz. Tempo presente)

(Os dois abraçados. Longa pausa)..."12

“(...) Ela - (...) Puxa, meu amor, que rosa linda, que coisa tão vermelha, que linda. Perdão, seu bobo, não sei, fiquei pateta com essa sua briga com o Portela e mas que rosa linda você... te amo, te amo... (Se abraçam. Dançam. Ela carregada de rosas)

Ele - Que você está dançando?

Ela - Eu, valsa.

Ele - Também vou dançar valsa, entăo. (Riem. Valsam. Riem cada vez mais) Que você está dançando?

Ela - Eu, valsa. (Ela sai com suas rosas. Ele continua dançando sozinho, rindo.) (Reversão de luz. Tempo presente). ${ }^{13}$

Sobre essa marcação coreográfica, Juliana - que se iniciou em dança pelo método Laban-Joss, com D. Maria Duschenes ${ }^{14}$, em São Paulo, e se aperfeiçoou no Mudra ${ }^{15}$, dirigido por Maurice Béjart, na Bélgica - acrescenta que não só haviam momentos de dança, como a peça toda era como uma dança. Nanini define a movimentaçăo como uma partitura com o corpo, em que: "tudo era planejado para subir com elegância, descer com suavidade, para não dar 'tranco' e não atrapalhar o sentido da frase, ou da idéia que você estava dizendo". Segundo o ator, apesar de Klauss não coreografar os movimentos dos atores, a marcação final era praticamente uma coreografia. Um trabalho que atendia às necessidades do ator, estimulando sua imaginação e oferecendo-Ihe apoio técnico. Nanini continuou freqüentando a aula de Klauss, onde trabalhava com um mapa do corpo humano, aprendendo a localizar a origem anatômica dos seus movimentos. ${ }^{18}$

Klauss Vianna descreve Aderbal, como uma pessoa muito aberta, que partindo das aulas de corpo, montou o espetáculo como se fosse um pas-de-deux, uma verdadeira coreografia com palavras. O diretor assume esse sentido de coreografia, relacio- 
nando-a à fala e à proxêmica e amplia o termo para a coreografia das palavras, e a coreografia das situaçōes, quando se refere à mise en scène ${ }^{17}$. Segundo ele, a encenação era exatamente uma dança, erguida junto à construçāo e desconstruçāo do cenário, e para qual, a contribuiçāo de Klauss Vianna foi fundamental:

(...) Começava o tablado, depois entrava uma cadeira, depois outra, uma mesa, uma janela, que saía, depois isso mudava de lugar e entrava um espelho, enfim, junto com essa construção e desconstrução do cenário, ia construindo essa dança, que dependia de uma relação com o texto (...) Como eu tinha um excelente preparador corporal, claro que a gente dialogava, mas sobretudo a participação fundamental do Klauss era um aprimoramento dos movimentos. Que pareciam fluentes, porque às vezes estava tudo nu, e era uma praia com detalhes de como ela se sentava ao pé dele, com um movimento preciso, quase de dança, como a própria dança final, com os dois em torno da mesa dançando a valsa. Tudo isso era marcaçăo dessa mise en scène, mas tudo era retrabalhado pelo Klauss, com um trabalho técnico primoroso e certamente, muitas vezes, com a contribuição de movimentos (...). ${ }^{18}$

Essa presença constante da dança, sobretudo a valsa ${ }^{19}$, pode ter influenciado a circularidade das marcaçōes, bastante destacada pela crítica na época, e considerada ironicamente por Aderbal, como um estigma na apreciação do seu trabalho, mas que nos remete à trajetória circular de um casal valsando num salāo. Como observou Macksen Luiz:

"(...) Aderbal usou o seu código muito pessoal de direção. Das marcaçōes circulares a uma exploração interpretativa detalhada, elaborou uma transcrição cênica a qual não escapou, sequer, da pesquisa sonora do rico diálogo. (...) As cenas se armam e se desfazem quase ao ritmo de valsa tocada ao sinal da inexorabilidade e da dependência da uniāo, e mantém uma circularidade de movimentos eficiente para demonstrar tanto a angústia das conversas à mesa do jantar quanto para revelar as fissuras do jogo do medo (...)., ${ }^{20}$

A técnica corporal de Klauss Vianna é identificada, pela crítica da época, como um importante aliado na construção de uma encenaçāo ágil, na qual a movimentação cênica dos atores constituiu um exercício extenuante e ininterrupto, de ritmo intenso, que reproduzia a tensão do conflito existencial ${ }^{21}$, vivido pelo casal. Uma integração no palco, que se parecia com um balé ${ }^{22}$, e para a qual os atores estavam tão afinados, que atingiram movimentos que sempre se completavam ${ }^{23}$ :

"É preciso considerar também que, além do talento do diretor, a equipe que criou este espetáculo é tão excepcional que tornou possível a concretização de todos os projetos da direção. Klauss Vianna amplia a significação de cada gesto sem comprometer a naturalidade das interpretaçōes. Há em cena um belo desenho, uma espécie de coreografia, representando o desejo, a aproximação e a solidão. ${ }^{24}$

O trabalho de corpo transparece ainda por intermédio das críticas recebidas pelos atores, com destaque para a técnica corporal de Juliana, que representava o combate, freqüentemente corporal entre o casal, com o corpo inteiro, surpreendendo pelo seu domínio da voz, posto que havia feito apenas um papel mudo ${ }^{25}$ no teatro brasileiro. E. no seu desempenho, foi notado uma elegância coreográfica, que imprimia leveza e musicalidade aos movimentos. A expressáo facial da atriz também foi analisada e comparada a uma máscara enigmática, que se prestava bem às controvérsias interiores da personagem $^{26}$. Nanini, que foi premiado com um Molière e um Mambembe, como o melhor ator do ano, pelo seu desempenho no espetáculo, recebeu igualmente críticas elogiosas, ressaltando-se sua presença cênica, como um ator que não perde um segundo da vida do personagem, e que estabelecia uma comovente comunicaçăo ${ }^{27} \mathrm{com}$ a platéia. O crítico Sábato Magaldi reconheceu no ator o gesto seguro e a inflexão corretíssima, numa justa medida, que caracterizava o estilo dos velhos monstros sagrados do teatro, destacando-o como o jovem galã mais talentoso da época ${ }^{26}$.

O espetáculo foi considerado como um trabalho enxuto, que valorizou os atores, numa montagem sóbria e despojada, quase desprovida de cenário, denotando um profundo amor pela obra. Recebeu inúmeros prêmios no Brasil, como o prêmio Inacen, como um dos cinco melhores espetáculos do ano, e o prêmio Florencio no Uruguai, como o melhor espetáculo estrangeiro, em 1985. A direção valeu a Aderbal Freire-Filho os prêmios Golfinho de Ouro e Mambembe, no Rio de Janeiro, e a Vianinha, um Mambembe Póstumo, como melhor autor. Esta encenação é assinalada no livro $\mathrm{A}$ dança ${ }^{29}$ de Klauss Vianna, como um dos seus últimos trabalhos junto ao teatro, pois na década de 80 , ele se voltou mais para a sua primeira instância, a dança. É curioso notar, como a mise en scène dessa montagem assumiu igualmente, uma conotação de dança, coincidindo com essa fase profissional de Klauss Vianna.

Mão na Luva, encerrou com maestria o trabalho de Klauss Vianna no teatro. Quando o diretor o definiu como um especialista, não empregou o termo em vão. Klauss já contava com cinqüenta e sete anos de idade e quarenta de profissão. Havia trabalhado durante uma década com inúmeros diretores e instruído vários corpos de atores, não só em cena, como também e principalmente, nas suas aulas. Logo o suporte técnico que ofereceu para a mise en scène de Aderbal, como notou o próprio diretor - foi insuperável.

Klauss Vianna seguiu o processo utilizado nas outras montagens, e dividiu o seu trabalho em duas etapas: o aquecimento, através da preparação corporal, que podia se estender até por quatro horas seguidas e o aprimoramento das marcaçóes, uma função reconhecida hoje como direção de movimento. No aquecimento, Klauss buscava ativar os músculos profundos dos atores - comumente desprogramados - e que funcionavam como um suporte físico para a emoção do personagem. Já na direção de movimento, ofereceu um apoio técnico substancial, pois mapeou os movimentos e identificou os seus apoios, limpando-os, para que os atores transmitissem plenamente suas intençōes. Um trabalho que se integrou de tal maneira à direção, que impregnou a encenaçāo com a dança, transformando a peça numa espécie de pas-de-deux.

Klauss trabalhou em inúmeras montagens na década de 70, no Rio de Janeiro, quer como coreógrafo, preparador corporal, ator e até mesmo diretor. Se considerarmos o número de 25 montagens, realizadas em 10 anos - de A Ópera de três vinténs ${ }^{30}$,

$96-$ Novembro $2004-\mathbb{N}^{\circ} 6$ 
em 1967 até O Exercício ${ }^{31}$, em 1977 -é possível obter uma média significativa de duas a três peças por ano. A diversidade de funçōes exercidas, bem como a extensāo do período abarcado, de 71 a 84 , denotam uma atividade em constante evoluçāo, na qual a expressão do corpo do ator constitui o foco principal, implicando ainda, no reconhecimento de público e crítica, que culminou em premiaçōes, como o Molière na categoria especial em 1972, por Hoje é dia de $r_{0} k^{32}$, e a indicação para o troféu Mambembe de melhor diretor e revelação em 1977 , por O Exercício.

Tomando-se por base os depoimentos de artistas envolvidos nas montagens destacadas, e as críticas coletadas nos jornais da época, foi possível traçar um perfil do contato de Klauss Vianna com o teatro, fator relevante no desdobramento de suas técnica. Acredito que refletir hoje sobre a preparação corporal do ator desenvolvida por ele na década de setenta, contribui para a compreensão dessa atividade, que vem se desenvolvendo nos últimos trinta anos no Brasil. A função do preparador corporal uma profissão constante no teatro hoje - que, sem dúvida, deve muito à memória física do trabalho de Klauss Vianna.

\section{NOTAS}

1 FILHO, Oduvaldo Vianna. "Mão na Luva". In.: O melhor teatro de Oduvaldo Vianna Filho/ seleção Yan Michalski. São Paulo: Global, 1984. 2ª ed. p. 127.

2 NANINI, Marco. In.: FRANCO, Marcella. "O afeto que se abre. O Vianinha amoroso volta em montagem de 'Mão na Luva', peça que o Vianinha político nunca teve coragem de mostrar". Jornal do Brasil. Caderno B. Rio de Janeiro, 22/08/2001. p. 02.

3 RIBEIRO, Joana. Entrevista com Marco Nanini. Rio de Janeiro, 2002.

4 VIANNA, Klauss. In.: "Esqueçam a forma, tudo é o movimento". A Tarde. Caderno 2, Fim de Semana. Bahia, 31/05/1986.

5 Os músculos adutores formam um agrupamento com cinco músculos, que ocupam a parte medial da coxa. São potentes adutores da coxa ao nível da articulação do quadril e contribuem para a rotação medial e flexão da coxa. São muito requisitados na dança, sofrendo portanto freqüentes rupturas.

6 CUNHA, Juliana Carneiro da. Depoimento sobre Klauss Vianna. Paris: e-mail, 2001. 7 RIBEIRO, Joana. Entrevista com Aderbal Freire-Filho. Rio de Janeiro, 2001.

8 CUNHA, Juliana Carneiro da. Depoimento sobre Klauss Vianna. Op. Cit.

9 RIBEIRO, Joana. Entrevista com Marco Nanini. Op. Cit.

10 "Mão na Luva" - de Vianinha, montagem de Aderbal Freire-Filho - arquivo pessoal do diretor - Rio de Janeiro, Teatro Gláucio Gill, 1984

11 FILHO, Oduvaldo Vianna. "Mão na Luva". In.: O melhor teatro de Oduvaldo Vianna Filho/ seleção Yan Michalski. Op. cit. p. 129

12 ldem Ibdem. p. 132.

13 ldem Ibdem. p. 137.

14 Nascida na Hungria, em 1922, radicada no país desde 1940, Maria Duschenes foi

98 - Novembro $2004-$ No $^{\circ}$ uma das introdutoras da dança educativa moderna no Brasil. Dedicando-se sobretudo à difusão dos ensinamentos de Laban, formou diversos bailarinos, coreógrafos, atores, professores de dança e de teatro. In.: http://infosampa.prodam.sp.gov.br/ccsp/danca/ mariaduschenes.asp

15 MUDRA, ou Centro de Aperfeiçoamento para o Intérprete Total. Escola criada pelo coreógrafo Maurice Béjart, em 1970, na Bélgica, que se distinguia por ensinar diversos estilos de dança, além do teatro e da música, durante um curso de três anos intensivos. Foi transferida para a Lausanne, sob o nome de RUDRA.

16 RIBEIRO, Joana. Entrevista com Marco Nanini. Op. cit.

17 Aderbal diferencia a mise en scène, da direção. Segundo ele, a primeira concerne à escritura cênica, a própria encenaçăo, e o segundo termo refere-se à condução do espetáculo, fazendo com que os atores cumpram a mise en scène, que pode ser construída a priori, ou ao longo dos ensaios.

18 RIBEIRO, Joana. Entrevista com Aderbal Freire-Filho. Op. cit.

19 A valsa é uma dança de par, de salão, cuja origem obscura é ligada a deutsche (alemã) e a landlër, no séc. XVIII. Teve seu apogeu no século XIX, em Viena na Áustria, devido ao compositor Strauss. De compasso ternário, com acento no primeiro tempo, evolui em deslocamento circular por meio de pequenos volteios, simbolizando uma época alegre e elegante.

20 MACKSEN, Luiz. "O jogo teatral em estado pleno". Jornal do Brasil. Caderno B. Rio de Janeiro, 17/12/1984. p. 02.

21KAUFFMAN, Rita. "Um hiato romântico na dramaturgia de Oduvaldo Vianna Filho". O Globo. Rio de Janeiro, 04/12/1984.

22 LIANO, Jr. Nelson. "Mão na Luva, um inédito de Vianinha menos político". Última Hora. Rio de Janeiro, 11/12/1984.

23 MACKSEN, Luiz. "O jogo teatral em estado pleno". Op. Cit.

24 LIMA, Mariângela Alves de. "Mão na Luva, espetáculo íntegro". O Estado de São Paulo. São Paulo, 30/09/1984. p. 41.

25 Juliana interpretou a personagem Marlene em As Lágrimas Amargas de Petra von Kant, de Fassbinder, que conferiu à atriz o prêmio de Revelação, pelo APCA de Sāo Paulo, em 1982.

26 MAGALDI, Sábato. "Mão na Luva, enésima prova de talento de Vianinha". Jornal da Tarde. Seção: Divirta-se. São Paulo, 22/09/1984. p. 11.

27 AYALA, Walmir. "Mão na Luva. Um estado de vida". Última Hora. Caderno Showbiz. Rio de Janeiro.

28 MAGALDI, Sábato. "Mão na Luva, enésima prova de talento de Vianinha". Op. cit. 29 VIANNA, Klauss e CARVALHO, Marco Antônio de. A dança. São Paulo: Siciliano, 1990. 1 a edição. p. 41.

30 A Ópera de Três Vinténs de Bertolt Brecht e Kurt Weill, direção de José Renato, com Fregolento, Marília Pêra, Oswaldo Loureiro e José Wilker, entre outros. Inaugurou a temporada de teatro na sala Cecília Meireles, em 1967. Foi a primeira montagem 
310 Exercício, de Lewis John Carlino, direçăo de Klauss Vianna, com Marília Pêra Gracindo Jr., estreou no Teatro Glória, em 1977.

32 Hoje é Dia de Rock, de José Vicente, direção de Rubens Corrêa, com Rubens Corrêa, Ivan de Albuquerque, Isabel Ribeiro e Leyla Ribeiro, entre outros. Estreou no Teatro Ipanema em 1971.

\section{BIBLIOGRAFIA}

AYALA, Walmir. Mão na Luva. Um Estado de Vida. Última Hora. Caderno Showbiz. Rio de Janeiro.

CUNHA, Juliana Carneiro da. Depoimento Concedido à Autora. Paris: e-mail, 2001 Doc. Inédito.

CURI, Norma. O Amor, a Outra Militância de Vianinha. Folha de São Paulo. São Paulo. FREIRE, Aderbal. Entrevista Concedida à Autora. Rio de Janeiro, 2001. Doc. Inédito. GERMAIN, Blandine Calais. Anatomia para o Movimento. Vol. 1 ell. São Paulo: Manole, 1992.

KAUFFMAN, Rita. Um Hiato Romântico na Dramaturgia de Oduvaldo Vianna Filho. 0 Globo. Rio de Janeiro, 04/12/1984

LIANO, Jr. Nelson. Măo na Luva, um Inédito de Vianinha Menos Político. Última Hora. Rio de Janeiro, 11/12/1984

LIMA, Mariângela Alves de. Mão na Luva, Espetáculo Íntegro. O Estado de São Paulo. São Paulo, 30/09/1984.

MACKSEN, Luiz. O Jogo Teatral em Estado Pleno. Jornal do Brasil. Caderno B. Rio de Janeiro, 17/12/1984. p02.

MAGALDI, Sábato. Mão na Luva, Enésima Prova de Talento de Vianinha. Jornal da Tarde. Seção: Divirta-se. São Paulo, 22/09/1984. p11.

NANINI, Marco. Entrevista Concedida à Autora. Rio de Janeiro, 2002. Doc. Inédito. PAVIS, Patrice. Dicionário de Teatro. São Paulo: Perspectiva, 1999.

PONZIO, Ana Francisca. Klauss Vianna - Um Incansável Pesquisador da Dança, ou do Corpo. O Estado de Săo Paulo. São Paulo.

RIBEIRO, Joana. A Técnica Klauss Vianna e sua Aplicação no Teatro Brasileiro. (Dissertação de mestrado). Rio de Janeiro: UNI-RIO, 2002.

VIANNA FILHO, Oduvaldo. Mão na Luva. In: O Melhor Teatro de Oduvaldo Vianna Filho. Seleção de Yan Michalski. São Paulo: Global, $2^{\mathbf{a}}$ ed., 1985.

VIANNA, Klauss. In.: Esqueçam a Forma, Tudo é o Movimento. A Tarde. Caderno 2, Fim de Semana. Bahia, 31/05/1986. VIANNA, Klauss e CARVALHO, Marco Antônio de. A Dança. São Paulo: Siciliano, 1990.
1 edição. http://infosampa.prodam.sp.gov.br/ccsp/danca/mariaduschenes.asp

\section{VIDEOTEIPE}

FREIRE, Aderbal. Mão na Luva - arquivo pessoal do diretor. Teatro Gláucio Gill: Rio de Janeiro, 1984. 